\title{
Lund -Mackay staging for rhinosinusitis, correlation between computed tomography scan score and intraoperative findings
}

\author{
Aljfout $\mathbf{Q}^{1}$, Rashdan $\mathbf{H}^{2}$, Maita $\mathrm{A}^{3}$, Saraireh $\mathbf{M}^{4}$, Alrefo $\mathrm{A}^{5}$, Hiari $\mathbf{M}^{6}$ \\ ${ }^{1}$ Dr Qais Aljfout, ${ }^{2}$ Dr Hesham Rashdan, ${ }^{3}$ Dr Abdullah Maita, ${ }^{4}$ Dr Mohammad Saraireh, ${ }^{5}$ Dr Abdelrazzag Alrefo, ${ }^{6}$ Dr \\ Mohammad Hiari. All are affiliated with Department of Otolaryngology, Royal Medical Services, Amman - Jordan
}

Address for Correspondence: Dr Qais Aljfout, Amman, Jordan, Email: qaisj@yahoo.com

\begin{abstract}
Objective: We have conducted this study to evaluate the accuracy of Lund - Mackay scoring system for rhinosinusitis with regards to time lag between dates of both CT scan and operation. Methods: A total of 120 rhinosinusitis patients, divided into three groups according to time lag between date of performing sinuses CT scan and date of surgery. Group A, the time lag was more than 8 weeks, in group B the time lag was 2-8 weeks, and group C, the time lag was less than two weeks. All patients underwent endoscopic sinus surgery; rhinosinusitis was staged using Lund - Mackay system and compared intraoperative findings using the same scoring system. Results: There was a significant difference in staging score in group A, and in group B although the difference was not statistically significant, it was scientifically noticed, in group $\mathrm{C}$ there was no difference between the preoperative and intraoperative scores. Conclusion: The correlation between Lund - Mackay staging and intraoperative finding in endoscopic sinus surgery depends on the time lag between scan date and surgery date, the shorter the time lag the better the correlation.
\end{abstract}

Keywords: Computed Tomography, Lund-Mackay, Paranasal Sinuses, Rhinosinusitis, Staging.

\section{Introduction}

Although the impact of chronic rhinosinusitis on the quality of life is proven, we have failed to recognize the best treatment modality to achieve best outcome, and this failure is a reflection of the lack of evidence regarding its pathogenesis [1], and although paranasal sinuses computed tomography scan is a prerequisite for endoscopic surgery., there are controversies regarding the best staging system to adopt for the evaluation of patients with regards to symptoms score and possible outcome of surgery [2,3]. There are many published staging systems like Levine and May staging system, Harvard staging system, Kennedy staging system, and Lund - Mackay system [4]. The last one is the most commonly used one worldwide. The Lund-Mackay staging system scores each sinus [anterior ethmoids, posterior ethmoids, maxillary, frontal, and sphenoid sinuses] according to the following scale: 0 [no opacification], 1 [partial opacification], or 2 [complete opacification]. The ostiomeatal complex is scored as 0 [not occluded] or 2 [occluded]. Left and right sides are

Manuscript received: $05^{\text {th }} \mathrm{Feb} 2016$

Reviewed: $15^{\text {th }}$ Feb 2016

Author Corrected: $25^{\text {th }}$ Feb 2016

Accepted for Publication: 03 ${ }^{\text {rd }}$ March 2016 staged separately and the scores are summed so that the total score range from 0 to 24 for each patient [5]. In this study, we have compared the preoperative Lund Mackay score with the intra-operative findings taking into consideration the time lag between computed tomography scan date and the date of surgery.

\section{Patients and Methods}

This is a prospective study, a total of 120 patients aged 16 to 68 years were included in this study, which was conducted from June 2014 till May 2015, patients consent and ethical committee approval of our institution were granted. All patients were scheduled to undergo endoscopic sinus surgery for medically refractory chronic rhinosinusitis.

All of the patients met the clinical criteria for the diagnosis of chronic rhinosinusitis, exclusion criteria includes orbital or intracranial complications of rhinosinusitis, previous sinus surgery, and history of systemic steroids use after CT imaging. 
All patients underwent CT scan of paranasal sinuses in the axial, coronal, and sagital planes, and then CT scans were studied and staged according to the Lund Mackay staging system a long with the standard demographic data. Staging was performed by two rhinologists.

Patients were divided into three groups according to the time lag between performing the computed tomography scan and date of surgery. Group A, the time lag was more than 8 weeks, in group B the time lag was 2-8 weeks, and group $\mathrm{C}$, the time lag was less than two weeks.

All patients underwent endoscopic sinus surgery; surgeries were performed by two surgeons who are familiar with the Lund - Mackay system.

SPSS for Windows was used for statistical analysis, using t-test and chi-squared tests when appropriate. All data are expressed as the mean \pm standard deviation (S.D.). A value of $\mathrm{P}<0.05$ was considered statistically significant.

\section{Results}

Our study groups were comparable for age, gender [p $>0.05]$. Group A composed of 22 [55\%] male patient and 18 [45\%] females, the mean age was $38.3 \pm 11.3$ years. Group B was composed of 19 [48\%] male patients and 21 [52\%] females with the mean age was $36.5 \pm 12.1$ years, and group $\mathrm{C}$ was composed of 20 male [50\%] and 20 female [50\%] with mean age of $36.1 \pm 13.3$ [table 1].

Preoperative staging of group A had a mean of 17.96 and a standard deviation of 4.21 while intraoperative staging had a mean of 14.20 and a standard deviation of 5.00, the $\mathrm{p}$ value using paired t-test was 0.0004 and this result showed that the difference is statistically significant. Group B, the preoperative staging had a mean of 18.8 and a standard deviation of 3.62 , and intraoperative staging had a mean of 17.40 with standard deviation of $3.25, \mathrm{p}$ value of 0.069 which is statistically not significant but considered scientifically significant. While in group $\mathrm{C}$, the preoperative staging had a mean of 17.30 with 3.71 as standard deviation and the intraoperative staging mean was 17.1 with 3.61 as standard deviation, and the $\mathrm{p}$ value was 0.83 , and this means that there was no difference between preoperative and intraoperative staging.

Table 1: Demographic data of our study groups

\begin{tabular}{|r|r|r|r|}
\hline Parameter & Group A & Group B & Group C \\
\hline Age (mean) \pm S.D. (years) & $38.3 \pm 11.3$ & $36.5 \pm 12.1$ & $36.1 \pm 13.3$ \\
\hline Sex (M:F) & $19: 21$ & $19: 21$ & $20: 20$ \\
\hline Total & $\mathbf{4 0}$ & $\mathbf{4 0}$ & $\mathbf{4 0}$ \\
\hline
\end{tabular}

Table 2: analysis data of the study groups

\begin{tabular}{|l|l|l|l|l|l|l|}
\cline { 2 - 7 } \multicolumn{1}{c|}{} & \multicolumn{2}{l|}{ Group A } & Group B & \multicolumn{2}{l|}{ Group C } \\
\cline { 2 - 7 } \multicolumn{1}{c|}{} & Preop. & Intraop. & Preop. & Intraop. & Preop. & Intraop. \\
\hline Mean & 17.96 & 14.20 & 18.80 & 17.40 & 17.3 & 17.1 \\
\hline Standard & 4.21 & 5.03 & 3.62 & 3.20 & 3.71 & 3.60 \\
\hline Total No. & 40 & 40 & 40 & 0.83 \\
\hline$P$ value & 0.0004 & 0.069 & & \\
\hline
\end{tabular}

\section{Discussion}

First, we want to emphasize that chronic rhinosinusitis is a clinical diagnosis, that there are benefits from endoscopic surgery [6,7]. There is a general agreement that computed tomography scan has high sensitivity for detection of mucosal inflammation in the paranasal sinuses [8]. And that computed tomography scan of paranasal sinuses is the gold standard imaging modality for the evaluation of patients with chronic rhinosinusitis. In addition to confirmation of diagnosis, it evaluates the extent of the disease, gives idea about the bony walls, orbit, and skull base; it helps to plan the surgery. Staging of rhinosinusitis help surgeons to plan the surgery, the sinuses need to be opened, the operative time needed, and the expected improvement on patient 
condition. Lund - Mackay score system is one of the most popular staging systems, it was evaluated in many aspects, linked to patients symptoms score [9] and evaluated with regards to incidence of intra-operative bleeding [10].Correlations between preoperative symptoms score and Lund - Mackay score were studied and had found that there was no correlation between them [11,12]. While others had found a correlation $[13,14]$.Others had found correlation between computed tomography scan score and post operative improvement in symptoms [15].

In our practice, we use Lund - Mackay system for the evaluation of our patients, and we had noticed that the extent of disease we expect to find during surgery does not correlate with the preoperative expectations based on Lund - Mackay score, and that's why we had evaluated the time lag between the scan and the date of surgery, and we are the first to do this.

We think that this is not a defect in this scoring system, but it is an important aspect that should be considered when surgeons use this system. Our finding that the correlation between Lund - Mackay score and intraoperative findings decreases with increased time lag between date of scan and date of surgery. Our study has limitations, of which is the effect of other co morbidities, effect of medications used in the time lag, and whether scans had been done after medical therapy or not. The new staging using volumetric scoring was found to have higher degree of correlation with regard to surgery outcome than Lund-Mackay system [16].

\section{Conclusion}

The correlation between Lund - Mackay staging and intraoperative finding in endoscopic sinus surgery depends on the time lag between scan date and surgery date, the shorter the time lag the better the correlation.

\section{Funding: Nil}

Conflict of interest: None.

Permission of IRB: Yes

\section{References}

1. H. Moghaddasi, M. Sanei Taheri, A.H. Jalali, M. Shakiba Correlation of Lund-Mackay and SNOT-20 Before and After Functional Endoscopic Sinus Surgery (FESS): Does the Baseline Data Predict the Response Rate? Iran J Radiol 2009, 6(4) 207-14.
2. Kenny TJ, Duncavage J, Bracikowski J, Yildirim A, Murray JJ, Tanner SB. Prospective analysis of sinus symptoms and correlation with paranasal computed tomography scan. Otolaryngol Head Neck Surg. 2001 Jul;125(1):40-3.

3. Bhattacharyya T, Piccirillo J, Wippold FJ 2nd. Relationship between patient-based descriptions of sinusitis and paranasal sinus computed tomographic findings. Arch Otolaryngol Head Neck Surg. 1997 Nov;123(11):1189-92.

4. Zinreich SJ. Imaging for staging of rhinosinusitis. Ann Otol Rhinol Laryngol Suppl. 2004 May;193:19-23.

5. Lund VJ, Mackay IS. Staging in rhinosinusitus. Rhinology. 1993 Dec;31(4):183-4.

6. Kennedy DW, Zinreich SJ, Shaalan H, Kuhn F, Naclerio R, Loch E. Endoscopic middle meatal antrostomy: theory, technique, and patency. Laryngoscope. 1987 Aug;97(8 Pt 3 Suppl 43):1-9.

7. Jakobsen J, Svendstrup F. Functional endoscopic sinus surgery in chronic sinusitis--a series of 237 consecutively operated patients. Acta Otolaryngol Suppl. 2000;543:158-61.

8. Bhattacharyya N, Jones DT, Hill M, Shapiro NL. The diagnostic accuracy of computed tomography in pediatric chronic rhinosinusitis. Arch Otolaryngol Head Neck Surg. 2004 Sep;130(9):1029-32.

9. Holbrook EH, Brown CL, Lyden ER, Leopold DA Lack of significant correlation between rhinosinusitis symptoms and specific regions of sinus computer tomography scans. Am J Rhinol 2005 19(4):382-387.

10. Mortuaire G, Bahij J, Maetz B, Chevalier D. LundMackay score is predictive of bleeding in ethmoidectomy for nasal polyposis. Rhinology. 2008 Dec;46(4):285-8.

11. Gheriani H, Curran A, Timon C. Endoscopic sinus surgery outcome in patients with symptomatic chronic rhino sinusitis and minimal changes on computerised Tomography. Irish Med J 2006 99:15-16. PMID 16506684

12. Yeak S, Siow JK, John AB. An audit of endoscopic sinus surgery. Singapore Med J. 1999 Jan;40(1):18-22. 
13. Smith TL, Mendolia-Loffredo S, Loehrl TA, Sparapani R, Laud PW, Nattinger AB. Predictive factors and outcomes in endoscopic sinus surgery for chronic rhinosinusitis. Laryngoscope. 2005 Dec;115(12):2199-205.

14. Sobol SE, Wright ED, Frenkiel S. One-year outcome analysis of functional endoscopic sinus surgery for chronic sinusitis. J Otolaryngol. 1998 Oct;27(5):252-7.

15. Wabnitz DA, Nair S, Wormald PJ. Correlation between preoperative symptom scores, quality-of-life questionnaires, and staging with computed tomography in patients with chronic rhinosinusitis. Am J Rhinol. 2005 Jan-Feb;19(1):91-6.

16. John Pallanch, Lifeng Yu, David Delone, Rich Robb, David R. Holmes III, Messr. Jon Camp. 3-D volumetric computed tomographic scoring as an objectiveoutcome measure for chronic rhinosinusitis: Clinical correlations and comparison to Lund-Mackay scoring. Int Forum Allergy Rhinol. 2013 December ; 3(12): 963-972.

\section{How to cite this article?}

Aljfout Q, Rashdan H, Maita A, Saraireh M, Alrefo A, Hiari M. Lund -Mackay staging for rhinosinusitis, correlation between computed tomography scan score and intraoperative findings. Int J Med Res Rev 2016;4(3):368-371. doi: 10.17511/ijmrr.2016.i03.14 